\title{
Identificación de biomarcadores sanguíneos para la detección de lesiones premalignas y el diagnóstico del cáncer gástrico
}

\section{Identification of Blood Biomarkers for Detecting Premalignant Lesions and Gastric Cancer}

\author{
Martin A. Gómez Zuleta, MD, ${ }^{1}$ Karen E. Torres, MSc, ${ }^{2}$ Michael T. Falduto, PhD, ${ }^{2}$ Scott R. Magnuson, PhD. ${ }^{2}$
}

\author{
Profesor asociado de Gastroenterología, Universidad \\ Nacional de Colombia. Gastroenterólogo, Hospital \\ Nacional Universitario UGEC. Bogotá, Colombia. \\ 2 Paradise Genomics Inc. Northbrook, Illinois EE. UU. \\ Fecha recibido: $\quad 05-11-15$ \\ Fecha aceptado: $16-12-16$
}

\section{Resumen}

Introducción: el cáncer gástrico es muy frecuente en Colombia y es la primera causa de muerte por cáncer. De acuerdo con la cascada de Correa existen unas etapas progresivas en la formación de esta enfermedad, que van de la gastritis, pasando por la atrofia, metaplasia y displasia, hasta el cáncer. En esas etapas intermedias se pudiera detectar y prevenir, pero no existen marcadores en sangre diferentes al pepsinógeno que puedan ayudar a detectar las etapas premalignas ni a diagnosticar el cáncer. Por lo cual, las investigaciones que ayuden a descubrir nuevos biomarcadores son de gran importancia.

Objetivos: el objetivo de este trabajo es identificar marcadores moleculares (perfil de expresión de ARNm) que distingan a los pacientes con condiciones premalignas (atrofia, metaplasia) y cáncer gástrico, de aquellos pacientes que solo tienen gastritis.

Metodología: se tomaron pacientes en cada una de las etapas de la cascada de Correa, los cuales proporcionaron una muestra, previo consentimiento firmado, de $2,5 \mathrm{~mL}$ de sangre en ayunas para el análisis de expresión de genes tomadas después de la endoscopia inicial. La sangre se colocó en un tubo de ARN sanguíneo PAXgene; luego, el ARN se extrajo de la sangre y se analizó usando una plataforma de microarrays, los cuales identificaron cambios de expresión de ARN mensajero que permitieron diferenciar cada una de las etapas descritas.

Resultados: se incluyeron 89 pacientes, y en los hallazgos endoscópicos se encontró gastritis crónica antral en 27 pacientes (30,3\%), cáncer gástrico avanzado en $25(28 \%)$, pangastritis crónica en $15(16,8 \%)$, cáncer temprano en $7(7,8 \%)$, sospecha de metaplasia intestinal en $6(6,7 \%)$, sospecha de gastritis atrófica en $3(3,3 \%)$ y úlcera péptica en 2 casos $(2,2 \%)$. Cuando se revisó el informe patológico se halló gastritis crónica en 34 pacientes (22 mujeres), adenocarcinoma intestinal en 20 (4 mujeres), metaplasia intestinal 18 casos (13 mujeres), cáncer tipo difuso en 11 (7 mujeres), displasia de bajo grado en 4 y de alto grado en 1, y atrofia sola en 1 paciente. En el análisis de expresión genética se encontraron 48 genes que permitieron determinar a los pacientes con gastritis crónica de aquellos con cáncer gástrico. También se hallaron 14 genes para diferenciar los pacientes con cáncer difuso de los de tipo intestinal, y un grupo de 48 genes que ayudó a distinguir los pacientes con gastritis crónica de los de metaplasia intestinal.

Conclusiones: este es el primer trabajo en Colombia, y a nivel mundial, que permite identificar nuevos biomarcadores a través de la expresión genética del ARN mensajero, el cual diferencia en sangre las etapas de la cascada de Correa, y permite diagnosticar el cáncer gástrico. Es probable que en un futuro se puedan utilizar como una prueba diagnóstica o de seguimiento.

Palabras clave

Cáncer gástrico, biomarcadores, prevención. 


\begin{abstract}
Introduction: Gastric cancer is very common in Colombia where it is the leading cause of death due to cancer. According to the Pelayo Corre, there is a cascade of stages from gastritis through atrophy, metaplasia and dysplasia to cancer. In the intermediate stages, it might be possible to detect and prevent the development of cancer, but there are no known markers in the blood other than pepsinogen to help to detect premalignant stages and diagnose cancer. Research is the key to discovery of new biomarkers.

Objective: The aim of this work is to identify molecular markers (mRNA expression profiles) that distinguish patients who have premalignant conditions (atrophy, metaplasia) and gastric cancer from patients who only have gastritis.

Methodology: Following an initial endoscopy, patients in each stage of the Pelayo cascade fasted and then provided a $2.5 \mathrm{ml}$ blood sample which was analyzed for gene expression. All participating patients signed consent forms prior to tests. The blood was placed in a PAXgene RNA Blood tube, RNA was extracted from the blood and then analyzed. A microarray platform which identified changes in messenger RNA expression was used to differentiate each of the stages described.

Results: Endoscopic findings for the eighty-nine patients included showed that 25 (28\%) had advanced gastric cancer, $7(7.8 \%)$ had early cancer, $27(30.3 \%)$ had chronic antral gastritis, $15(16.8 \%)$ had chronic pangastritis, three $(3.3 \%)$ were suspected of having atrophic gastritis, six $(6.7 \%)$ were suspected of having intestinal metaplasia, and two $(2.2 \%)$ had peptic ulcers. Pathological reports showed 20 cases of intestinal adenocarcinoma (4 women), 11 cases diffuse cancer (7 women), 34 cases of chronic gastritis (22 women), one case of atrophy alone, 18 cases of intestinal metaplasia (13 women), four cases of low-grade dysplasia, and one case of high-grade dysplasia. The analysis of genetic expression found 48 genes which could be used for differentiation of patients with chronic gastritis from patients with gastric cancer. We also found 14 genes that could be used to differentiate patients with diffuse cancer from patients with intestinal type gastric cancer, and a group of 48 genes that could be used to differentiate patients with chronic gastritis from those with intestinal metaplasia.

Conclusions: This is the first work anywhere in the world that has identified new biomarkers through the genetic expression of messenger RNA which differentiates the stages of the Pelayo Correa cascade and permits diagnosis of gastric cancer. It is likely that in the future they may be used as diagnostic and/or followup tests.
\end{abstract}

\title{
Keywords
}

Gastric cancer, biomarkers, prevention.

\section{INTRODUCCIÓN}

El cáncer gástrico es una entidad multifactorial, con una alta prevalencia. En 2012 se presentaron más de 1 millón de casos nuevos, y cerca de dos terceras partes ocurrieron en países en desarrollo. Las zonas de alto riesgo incluyen el este de Asia (China y Japón), Europa Oriental y partes de centro y sur de América. A nivel mundial, el cáncer gástrico es el quinto tipo de cáncer que ocurre con mayor frecuencia, y la segunda causa de muerte por cáncer, pero en Japón es la primera causa de muerte por cáncer; mientras que, en Colombia, la incidencia es 10 veces más alta que en EE. UU. (1-8).

De acuerdo con la clasificación de Lauren, histológicamente el cáncer gástrico (CG) se divide en dos tipos: intestinal y difuso. estos tipos de tumores tienen claras diferencias desde el punto de vista epidemiológico, histopatológico, endoscópico, clínico y patogenético (9-12).

El CG de tipo intestinal es una enfermedad multifactorial que se desarrolla a través de un proceso de múltiples pasos que puede durar 20 años o más, y que, según el modelo de la carcinogénesis gástrica propuesto por Correa, se inicia con gastritis crónica producida por $H$. pylori, la cual progresa a atrofia gástrica, metaplasia intestinal, displasia y, finalmente, cáncer. En este modelo, la atrofia gástrica y la metaplasia intestinal se consideran condiciones precursoras del CG. La aparición final del tumor involucra la participación de otros dos factores: medioambientales, como falta de consumo de verduras o frutas, consumo excesivo de sal; y genéticos del huésped. Entre los factores genéticos se estudiaron polimorfismos genéticos de respuesta inmune, así como sus productos proteicos. Entre estos, se encuentran los genes de las citocinas, involucrados en el sistema inmune adaptativo, y factores de reconocimiento de patrones que inician la respuesta del sistema inmune innato (13-15).

La causa de la alta mortalidad del CG se debe fundamentalmente a un diagnóstico tardío. Cuando se detecta tempranamente la sobrevida a 5 años es de $90 \%$; en cambio, cuando se hace en estadios avanzados es de $15 \%$ a $20 \%$ (16). Desafortunadamente en países en vía de desarrollo, la mayoría de los pacientes con CG se detectan en estados 
avanzados cuando el pronóstico es muy malo. Por ello, es muy importante identificar los estados premalignos de atrofia, metaplasia intestinal y displasia, para vigilarlos.

Generalmente, cuando el CG está en un estadio temprano, infortunadamente cuando los pacientes tienen lesiones premalignas o incluso presentan el cáncer en su fase temprana, la mayoría está completamente asintomático. En el momento en que presentan síntomas de alarma, como sangrado o pérdida de peso, y consultan, el CG ya está muy avanzado.

Japón es pionero en programas de tamización de CG, cuyo objetivo es identificar CG en estadios tempranos con el fin de ofrecer un tratamiento oportuno. Para este propósito se utilizan radiografías gástricas con bario anuales en personas mayores de 40 años $(15,16)$. A pesar de esto, solo $10 \%$ de la población candidata para la tamización se somete a este método (17). Otra opción es realizar endoscopias (EVDA) de forma masiva; sin embargo, la aceptación de las personas sintomáticas no es la ideal y, por tanto, la inmensa mayoría no se somete a los estudios, además que esta estrategia es costosa y, en ciertas áreas, podría no ser costo efectivo.

Por ello, como medida de prevención, sería ideal tener marcadores serológicos fiables que permitan detectar las condiciones premalignas o el CG antes que lleguen al cáncer avanzado. Desde hace más de 20 años se describió un método serológico que busca determinar solo la existencia de atrofia de una manera no invasiva sin la necesidad de endoscopia, mediante la medición de pepsinógenos (PG) en sangre. Los PG séricos se clasifican en dos tipos: PG-I, o PG-A, y el PG-II, o PG-C, los cuales son bioquímica e inmunológicamente distintos (18-20).

El PG-I se produce por las células principales y mucosas del cuello glandular de las glándulas del fondo; el PG-II se forma por esas mismas células, y también por las células de las glándulas antrales y las glándulas de Brunner. Así, conforme se produce atrofia en el cuerpo gástrico proximal, progresivamente se disminuyen los niveles de PG-I, mientras que los de PG-II permanecen constantes, por lo que se origina una disminución progresiva del PG-I y de la relación PG-I/PG-II, lo que refleja la progresión de mucosa gástrica normal a gastritis crónica atrófica. Los valores que reflejan atrofia son PG-I menor de $70 \mathrm{ng} / \mathrm{mL}$ y relación PG-I/PG-II menor de 3; sin embargo, este método no se acepta ampliamente ya que solo busca detectar atrofia, no identifica la metaplasia intestinal ni el cáncer, es costoso y no está disponible en el medio (18-22).

Por todo esto, se cree que el método para identificar a las personas en riesgo de CG, o con CG temprano, no solo debe ser simple, sino también efectivo y de bajo costo, como el antígeno prostático para cáncer de próstata; asimismo, deber ser útil para detectar atrofia y metaplasia intestinal (mayor riesgo de CG), así como el cáncer gástrico mismo, con el fin de poder llegar a un mayor número de pacientes y que sea más efectivo o tenga una mayor utilidad clínica. Al respecto, algunos grupos recomiendan utilizar la combinación de la determinación de la infección por $H$. pylori y biomarcadores séricos de atrofia, como el PG; sin embargo, esta estrategia no detectaría a los pacientes con metaplasia, ni a los pacientes con cáncer temprano, ya que no existen marcadores serológicos para ello. De allí la necesidad de plantear estudios de investigación que permitan encontrar nuevos marcadores en sangre para identificar las diferentes etapas de la cascada de Correa (atrofia, metaplasia, displasia, cáncer gástrico temprano y, finalmente, cáncer avanzado) (23).

Recientemente, se encontró que los factores trefoil (TFF), los cuales son moléculas pequeñas y estables $(12-22 \mathrm{Kd})$ secretadas por células del tracto gastrointestinal, junto con los pepsinógenos séricos pudieran ser nuevos biomarcadores con más rendimiento que los PG solos para predecir la existencia de atrofia. Cuando se combina el TFF3 con PG-I y con la relación PG-I/PG-II, la sensibilidad para detectar atrofia es de $80 \%$ comparado con $67 \%$ para los PG solos; sin embargo, de nuevo este marcador solo evalúa la atrofia $(24,25)$.

Existen otros biomarcadores que también se quieren usar, estos son los microARN (miARN). Este es un ARN monocatenario con una longitud de entre 21 y 25 nucleótidos, que tiene la capacidad de regular la expresión de otros genes mediante diversos procesos, utilizando para ello la ruta de ribointerferencia. Se observó que el patrón miARN se correlaciona con el número de células tumorales circulantes y, por tanto, los miARN en sangre periférica pueden ser más una herramienta para el seguimiento que para el diagnóstico del cáncer. Se observa un patrón miARN diferente en el tejido de cáncer gástrico en comparación con el tejido no maligno de un mismo paciente; sin embargo, no se ha podido utilizar como un biomarcador ya que el perfil de miARN no es idéntico en los diferentes estudios y, además, no se evaluó en las fases premalignas de la enfermedad (26).

Como se puede deducir, en la actualidad no existen marcadores sanguíneos que permitan identificar adecuadamente las etapas por las que pasa un paciente hasta llegar al cáncer gástrico, cascada de Correa, lo cual hace imperativo desarrollar protocolos de investigación en esta área que busquen la identificación de estos biomarcadores y su subsecuente aplicación en campañas de prevención de esta terrible enfermedad, la cual mata a más de 800000 personas en el mundo al año, en Colombia alrededor de 50000 (más que las muertes violentas), lo que la convierte en la primera causa de muerte por cáncer $(1,7)$.

Por otro lado, se sabe que los tumores malignos y el cáncer metastásico tiene un profundo efecto fisiopatológico en 
múltiples órganos y sistemas del cuerpo humano. Por este efecto sistémico, el cáncer es propenso a mediar cambios en las células blancas de la sangre debido tanto a una respuesta directa de la señalización de factores secretados producidos por los tumores, como indirectamente a partir de la reacción, a un estrés fisiológico, de las células blancas de la sangre (27). Además, se sabe que las células blancas, como mediadores de la respuesta inmune, producen antígenos contra los marcadores tumorales y tienen un papel en la defensa contra los tumores primarios y metástasis (28).

Ya que, en gran parte, estas respuestas se deben a las alteraciones en las proteínas celulares, codificado por genes de estas células blancas, es probable que las células blancas tengan programas específicos de expresión genética en la presencia de un tumor (figura 1). Si estos perfiles se pueden correlacionar con el tamaño, localización o etapa del cáncer, y progresión, esto podrían servir como biomarcador para el diagnóstico del cáncer gástrico, su pronóstico, control terapéutico o como coadyuvantes para los medicamentos contra el cáncer (figura 2).

El objetivo principal de este trabajo es determinar los perfiles de expresión genética a partir de la sangre total de pacientes sometidos a endoscopia digestiva superior en las diferentes etapas de la cascada de Correa, desde la gastritis hasta el cáncer gástrico avanzado.

\section{OBJETIVOS}

\section{General}

Identificar marcadores moleculares (perfil de expresión de ARNm) que distingan los casos, condiciones premalignas como atrofia, metaplasia y cáncer gástrico, de los controles, pacientes con dispepsia que solo tienen gastritis. El objetivo es desarrollar un perfil de expresión a base de sangre que tenga una alta sensibilidad y especificidad para diferenciar los pacientes sanos, o con gastritis, de aquellos que presentan cáncer gástrico o condiciones premalignas. Se cree que la identificación de este perfil de expresión será de gran ayuda en el diagnóstico de esta grave enfermedad.

\section{Específicos}

- Identificar, en la población colombiana, un perfil de expresión genética que permita reconocer la gastritis crónica atrófica.

- Establecer un perfil de expresión genética de metaplasia intestinal completa.

- Determinar un perfil de expresión genética de displasia de bajo o alto grado.

- Fijar un perfil de expresión genética de cáncer gástrico.

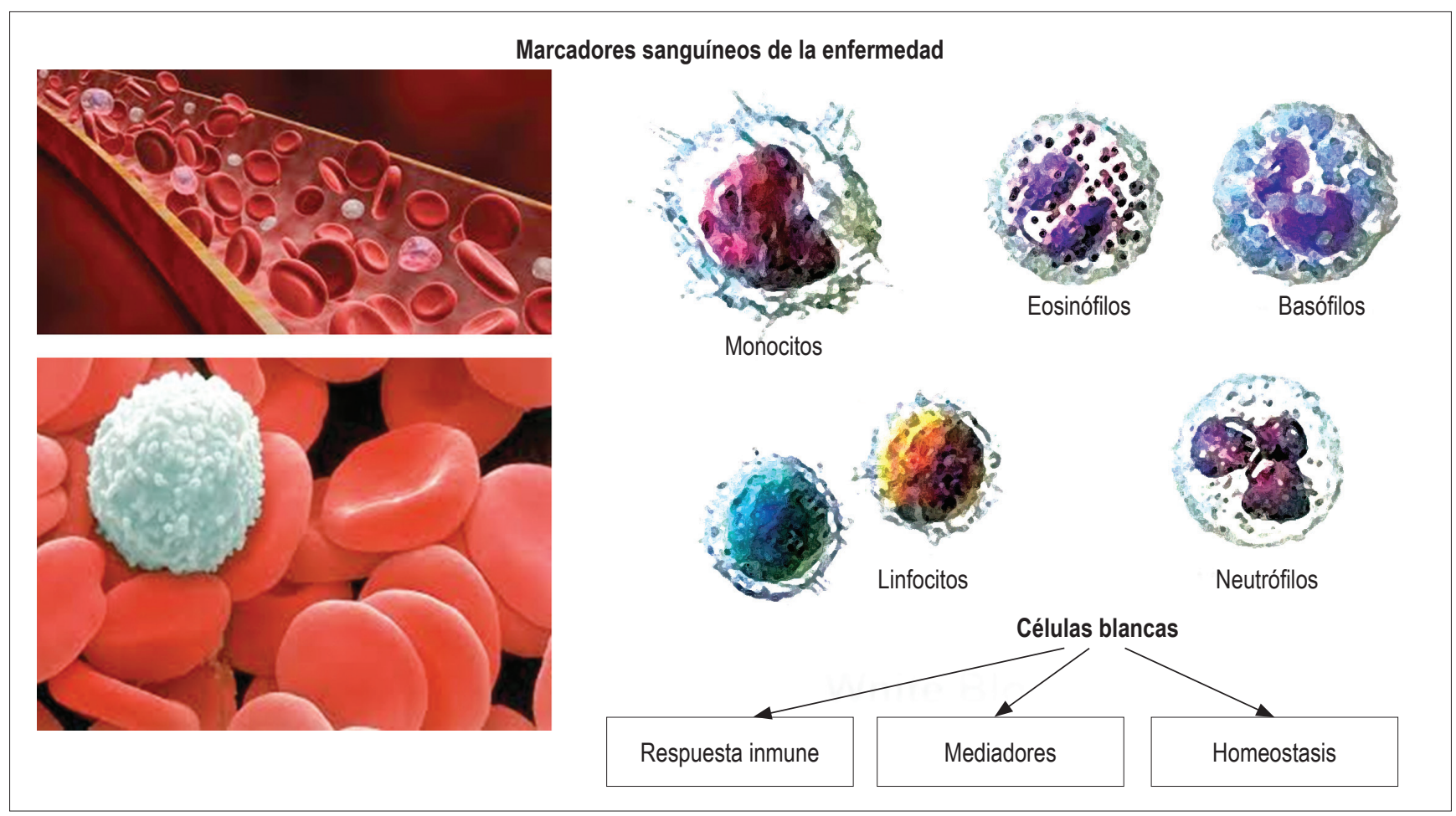

Figura 1. Las células blancas se encargan del homeostasis, son mediadores o se dan debido a una respuesta inmune, de acuerdo con sus necesidades. 


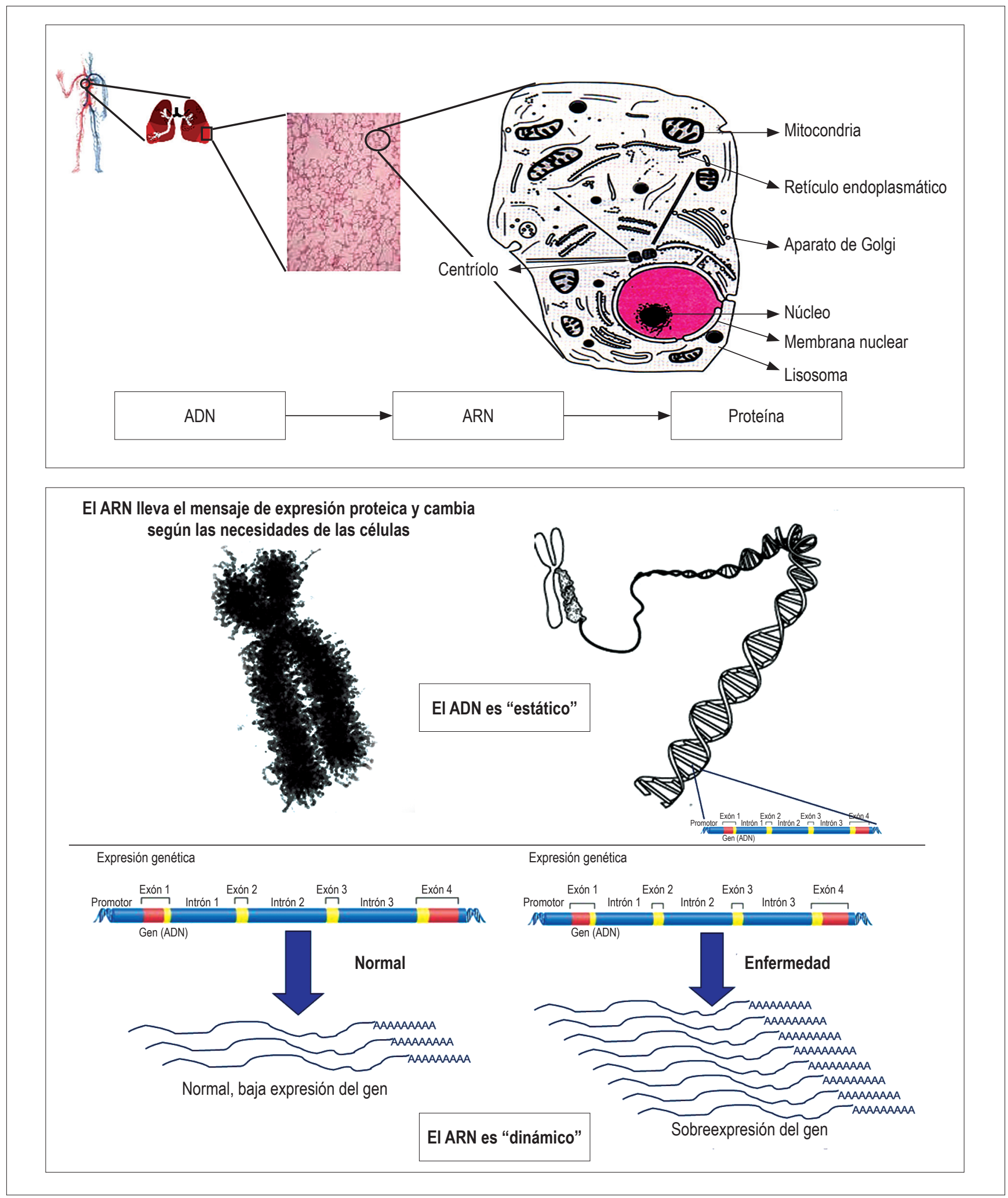

Figura 2. El ARN es el resultado de la traducción del ADN y lleva a la expresión proteica; este es dinámico, a diferencia del ADN que es estático. 


\section{MATERIALES Y MÉTODOS}

En el estudio se incluyeron, de manera prospectiva, pacientes que asistieran al servicio de gastroenterología del Hospital el Tunal-Universidad Nacional de Colombia (Bogotá) para la realización de endoscopia digestiva alta (EVDA). Todos los pacientes firmaron el consentimiento informado después de una explicación completa y detallada sobre esta investigación. Tanto el protocolo de investigación como el consentimiento informado se aprobaron por el Comité de Investigaciones y el Comité de Ética del Hospital el Tunal.

Antes de realizar la EVDA, los pacientes contestaron un formulario previamente diseñado que contenía las variables epidemiológicas y demográficas más importantes en cáncer gástrico. Todos los pacientes estaban en ayunas y se registró el consumo de cualquier medicamento, así como el de algunos alimentos.

En todos los pacientes, la endoscopia digestiva se realizó por la mañana, después de un ayuno mínimo de 6 horas, en decúbito lateral izquierdo. A todos los pacientes se les aplicó lidocaína en atomizador (Roxicaina, solución tópica, Ropsohn Therapeutics) utilizando 2 aplicaciones (20 mg) para anestesiar la faringe. Las muestras para el estudio histopatológico fueron de la siguiente manera: 3 del antro, marcadas como tubo A; 2 de cuerpo, marcadas como tubo B; y 2 para la infección por Helicobacter pylori. Luego, las biopsias se sumergieron en formol neutro tamponado al $10 \%$, y se remitieron al laboratorio del hospital para su procesamiento convencional a la espera de un diagnóstico histológico.

Después de la endoscopia, y de la recuperación, se tomó una muestra de $2,5 \mathrm{~mL}$ de sangre total para el estudio. Luego, los resultados del perfil de expresión genética se compararon con los resultados de la patología, para correlacionar la presencia de atrofia, metaplasia, displasia o cáncer. En total, se calculó un tamaño de muestra de 100 pacientes sumando todos los grupos.

\section{Criterios de inclusión}

\section{Casos}

- Pacientes $(\mathrm{n}=20)$ con sospecha endoscópica de cáncer gástrico.

- Pacientes con sospecha, por endoscopia, de atrofia $(n=20)$, metaplasia (20 pacientes) o displasia (20 pacientes).

\section{Controles}

- Pacientes $(n=20)$ con diagnóstico endoscópico de gastritis crónica, la cual luego se confirmó por la patología.

\section{Criterios de exclusión}

\section{Casos y controles}

- Uso actual de narcóticos.

- Infección activa de cualquier tipo.

- Antibióticos prescritos actuales.

- Antecedente de algún otro tipo de cáncer (excluyendo cáncer de piel, melanoma o gástrico).

- También se excluyeron pacientes con enfermedades concomitantes serias, como insuficiencia cardíaca congestiva (ICC); accidente cerebrovascular (ACV); diabetes descompensada; alteraciones de la coagulación; cirrosis; cirugía gástrica previa; embarazadas o en período de lactancia; adicción a drogas o alcohol o enfermedades psiquiátricas; infección por VIH; anticoagulados; y pacientes con cáncer o que recibieran quimioterapia.

\section{Procedimientos del estudio}

Los casos y controles proporcionaron una muestra, previo consentimiento firmado, de $2,5 \mathrm{~mL}$ de sangre en ayunas para el análisis de expresión de genes, la cual se tomó después de la endoscopia inicial. La sangre se colocó en un tubo de ARN sanguíneo PAXgene, luego se invirtió 8-10 veces, se incubó a temperatura ambiente durante 2-8 horas y se almacenó a $-20^{\circ} \mathrm{C}$ (congelador) hasta su envío en lote al laboratorio de referencia para su procesamiento y análisis.

El ARN se extrajo de la sangre y se analizó usando una plataforma de microarrays que identificó cambios de expresión de ARN mensajero, lo que permitió diferenciar los casos de los controles (figura 3 ).

\section{Procesamiento de las muestras}

El procesamiento de la muestra implica el aislamiento de ARN total usando modificaciones de los procedimientos estándar que involucran extracción y purificación orgánica (29). La calidad y cantidad del ARN total se evaluó por espectrofotometría y el equipo Agilent Bioanalyzer. Las muestras de ARN total se amplificaron y se prepararon para la hibridación de microarrays utilizando una reacción de trascripción in vitro con nucleótido marcado.

La calidad y cantidad del ARN complementario resultante (ARNc) también se evaluó mediante espectrofotometría y el equipo Agilent Bioanalyzer antes de la hibridación. El ARNc se hibridó con sondas de ADN en SurePrint G3 Human Gene Expression 8x60K v2 Microarrays de Agilent Technologies. El estudio se realizó con la última versión de 


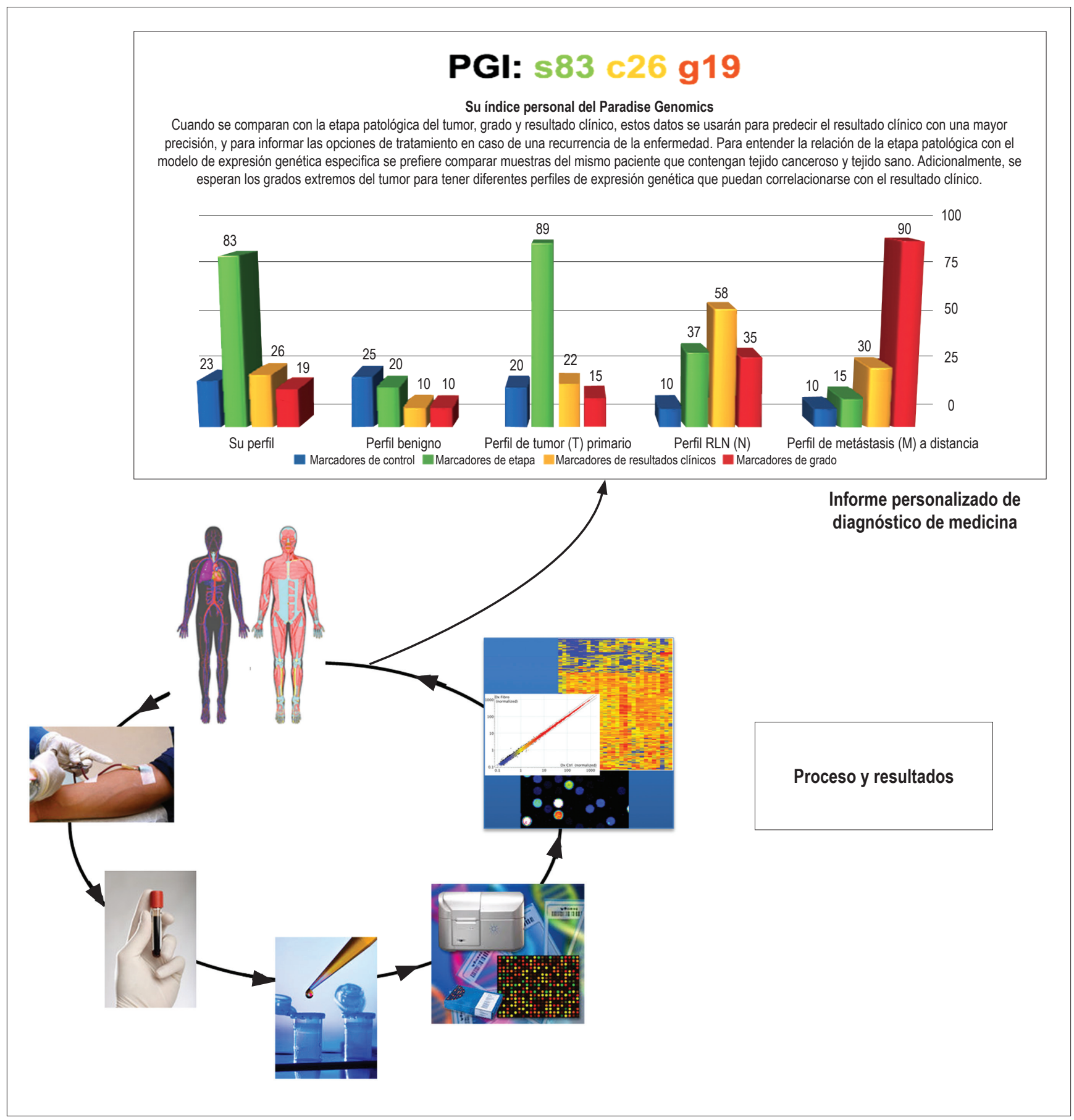

Figura 3. Se muestra gráficamente como fue el proceso de recolección de la muestra hasta su análisis.

microarrays de todo el genoma humano, la cual se dirige a 50599 características biológicas diferentes (29). Después de la hibridación, las matrices se lavaron y se escanearon en alta resolución en el escáner Agilent Microarray SureScan con rango dinámico ampliado (figura 4).
Finalmente, las imágenes del microarray (figura 5) se inspeccionaron visualmente y se obtuvieron los datos utilizando el software Agilent Feature Extraction, que genera métricas de control de calidad para cada punto en la matriz. Cualquiera matriz que no cumplió con las estrictas normas 


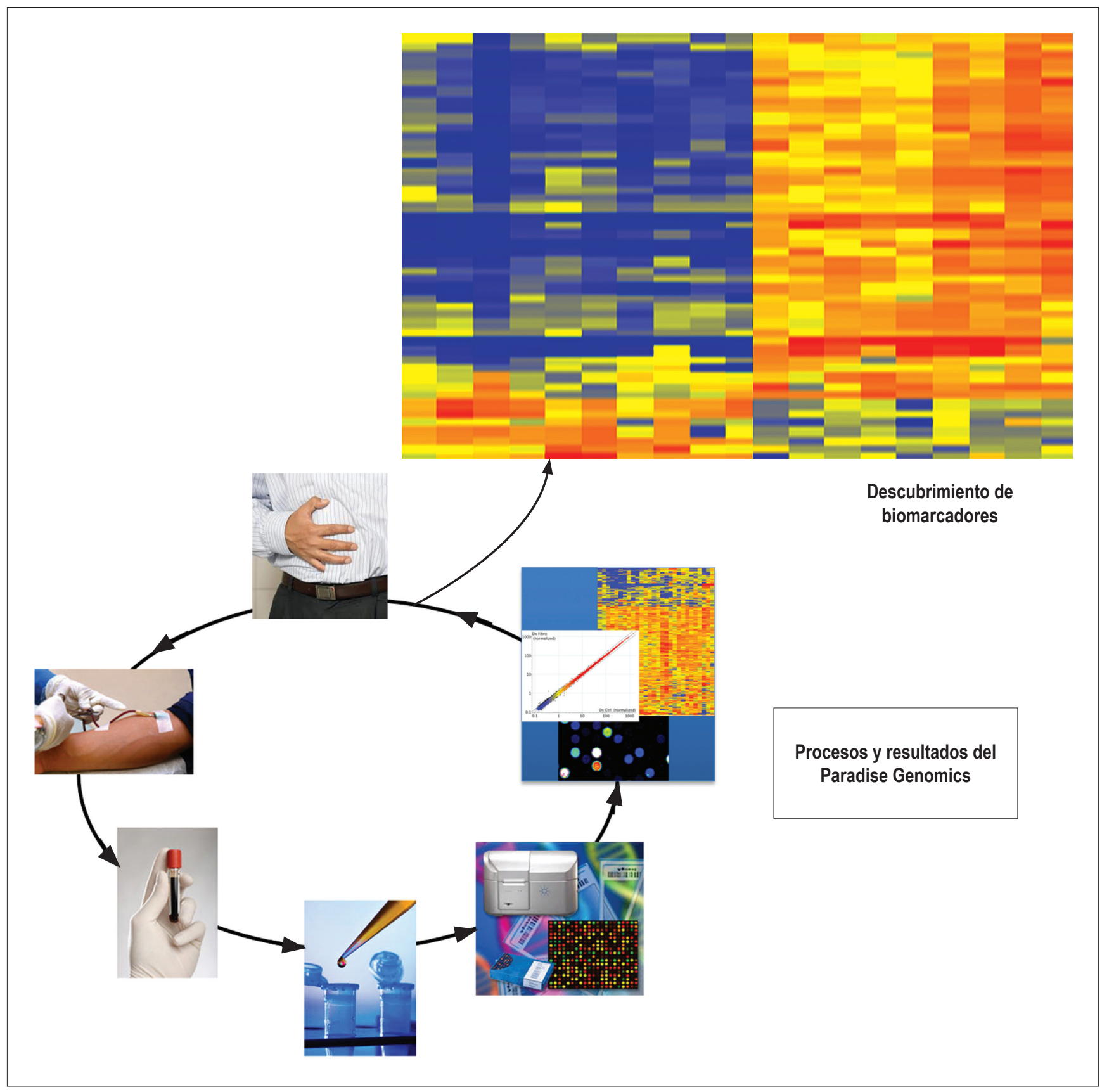

Figura 4. En la imagen se muestra cómo se procesó la muestra hasta su resultado.

de calidad se repitieron para asegurar que los datos fueran de la mayor calidad y el conjunto de biomarcadores fueran lo más reproducible y sensible posible.

\section{Análisis estadístico}

Se realizó una descripción estadística de las variables previamente descritas, de tal forma que las variables cualitati- vas se expresaran en términos de porcentajes, y las variables numéricas en promedios.

Los datos en bruto se normalizaron en toda la matriz mediante métodos de normalización global para la comparación constante de matriz a matriz. Los análisis de los datos y la identificación de los biomarcadores incluyo visualización estadística, que comprende la agrupación jerárquica y mapas de calor, gráficos de dispersión y diagramas de Venn (30). 


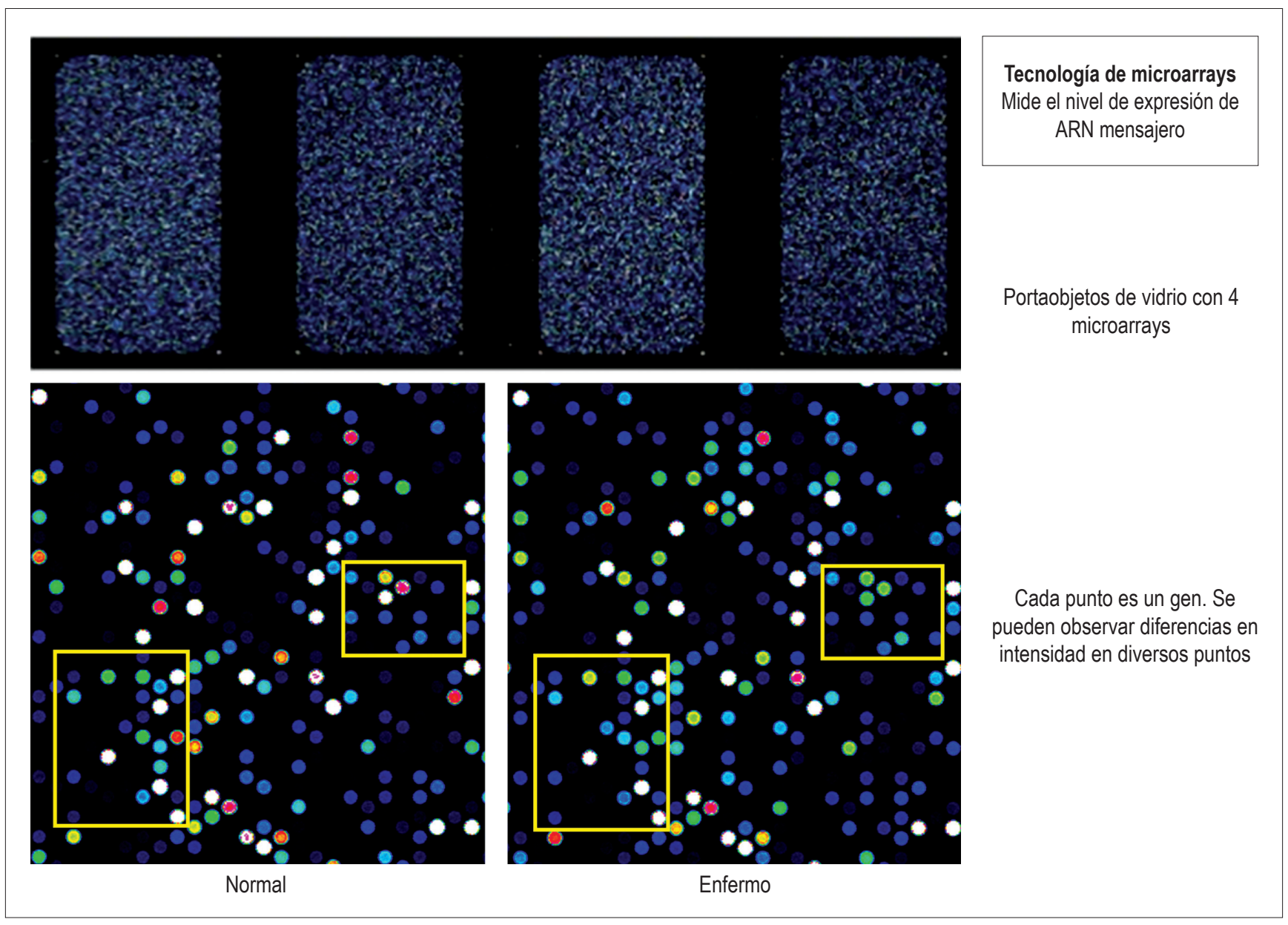

Figura 5. La gráfica muestra como es la tecnología de microarray cuando se utiliza, la cual permite identificar los genes involucrados en cada etapa de la cascada de Correa.

\section{RESULTADOS}

En total, se logró incluir 89 pacientes con un promedio de edad de 59,5 años. El 57\% fue mujeres, las indicaciones de la endoscopia fueron: dispepsia $75 \%$, anemia $4,4 \%$, pérdida de peso $5,56 \%$ y hemorragia de vías digestivas altas $8,8 \%$.

En los hallazgos endoscópicos se encontró gastritis crónica antral en 27 de los pacientes (30,4\%), cáncer gástrico avanzado en 25 (28\%), pangastritis crónica 15 (16,8\%), cáncer temprano en $7(7,8 \%)$, sospecha de metaplasia intestinal en $6(6,7 \%)$, sospecha de gastritis atrófica en 3 $(3,3 \%)$ y úlcera péptica en 2 casos $(2,2 \%)$.

Cuando se revisó el informe patológico se encontró gastritis crónica en 34 pacientes ( 22 mujeres); adenocarcinoma intestinal en 20 (4 mujeres); metaplasia intestinal en 18 ( 13 mujeres); cáncer tipo difuso en 11 ( 7 mujeres); displasia de bajo grado en 4 y de alto grado en 1 pacientes; $y$ atrofia sola en 1 paciente. De los 89 pacientes, $56(67,2 \%)$ tenían la infección por Helicobacter pylori.
De los pacientes con cáncer gástrico se realizó una TAC abdominal a 31, entre avanzados y tempranos, y se encontró que $6(25,8 \%)$ estaban en estadio I, es decir, temprano; 4 en estadio II; 7 en estadio III; y 14 (61\%) en estadio IV o con metástasis. En cuanto a la ubicación del tumor, solo 4 $(12,9 \%)$ de los 31 se ubicaban en el cardias.

En cuanto al perfil de expresión genética, además del descrito en la metodología, cuando se realizó el análisis, los genes que se expresaron diferencialmente entre hombres y mujeres se retiraron del análisis. Solo se utilizaron los genes que se expresaron diferencialmente más de 1,5 veces y con valores T-test de $p 0,01$ o menos.

De toda la expresión genética evaluada en las muestras de sangre se logró descubrir genes expresados diferencialmente que pueden utilizarse para distinguir pacientes con gastritis crónica de pacientes con cáncer gástrico difuso, y de aquellos con adenocarcinoma intestinal. Las siguientes figuras representan árboles jerárquicos, también llamados mapas de calor, que permiten discriminar 
una patología de la otra con base en la expresión genética (figura 6).

Cuando se analizó el informe patológico y se realizó una validación cruzada de todas las muestras patológicas contra los 49 genes encontrados utilizando un algoritmo de predicción de clase se encontró que al comparar el grupo de pacientes con gastritis crónica $(\mathrm{n}=34)$ con todos los pacientes diagnosticados con cáncer intestinal o difuso $(n=31)$ se logró una precisión general de $97 \%$ con una sensibilidad de $97 \%$ y especificidad de $97 \%$.

Además, se encontró que los perfiles de expresión genética en la sangre de los dos tipos de cáncer son distintos de la gastritis, y al hacer también la agrupación jerárquica de la expresión génica entre cáncer difuso y adenocarcinoma se encontraron 14 genes diferentes que pueden diferenciar completamente pacientes con cáncer difuso $(\mathrm{n}=11)$ de aquellos con adenocarcinoma $(n=20)$, con excepción de un paciente con adenocarcinoma (figura 7).

Para diferenciar a los pacientes con gastritis crónica de pacientes con metaplasia intestinal se encontró un perfil de expresión de 48 genes distintos. Al comparar este grupo de genes con el diagnóstico patológico, la exactitud de la agrupación jerárquica de estos genes fue del $100 \%$, sin falsos positivos o falsos negativos (figura 8) (15).

\section{DISCUSIÓN}

El cáncer gástrico es la quinta causa de cáncer en el mundo, pero la segunda causa de mortalidad, lo cual da una idea de su alto índice de letalidad. Existen dos tipos principales, el difuso y el adenocarcinoma, este último es el más frecuente y se sabe que pasa por una secuencia de eventos que van desde la gastritis crónica hasta el cáncer avanzado, lo cual se recrea en la denominada cascada de Correa (11). En esta cascada de eventos que llevan al cáncer intervienen factores ambientales, genéticos y la infección por H. pylori.

Para desarrollar cáncer avanzado pasa mucho tiempo y, es en ese período que, como médicos, se puede intervenir al detectar la enfermedad en sus fases iniciales, como en la atrofia, metaplasia o displasia; sin embargo, como se vio, no existen casi pruebas que permitan conocer de manera sencilla estas etapas, aunque se describen algunas, estas no están disponibles en la práctica clínica, a excepción del pepsinógeno, pero este solo permite evaluar si el paciente tiene atrofia. En Colombia parece que no es muy útil de acuerdo con los resultados informados recientemente por Martínez y colaboradores del grupo del Instituto de Cancerología, $(23,31)$.

Es claro que los marcadores tradicionales de cáncer, como CAE y CA19-9, no son útiles para el diagnóstico del cáncer

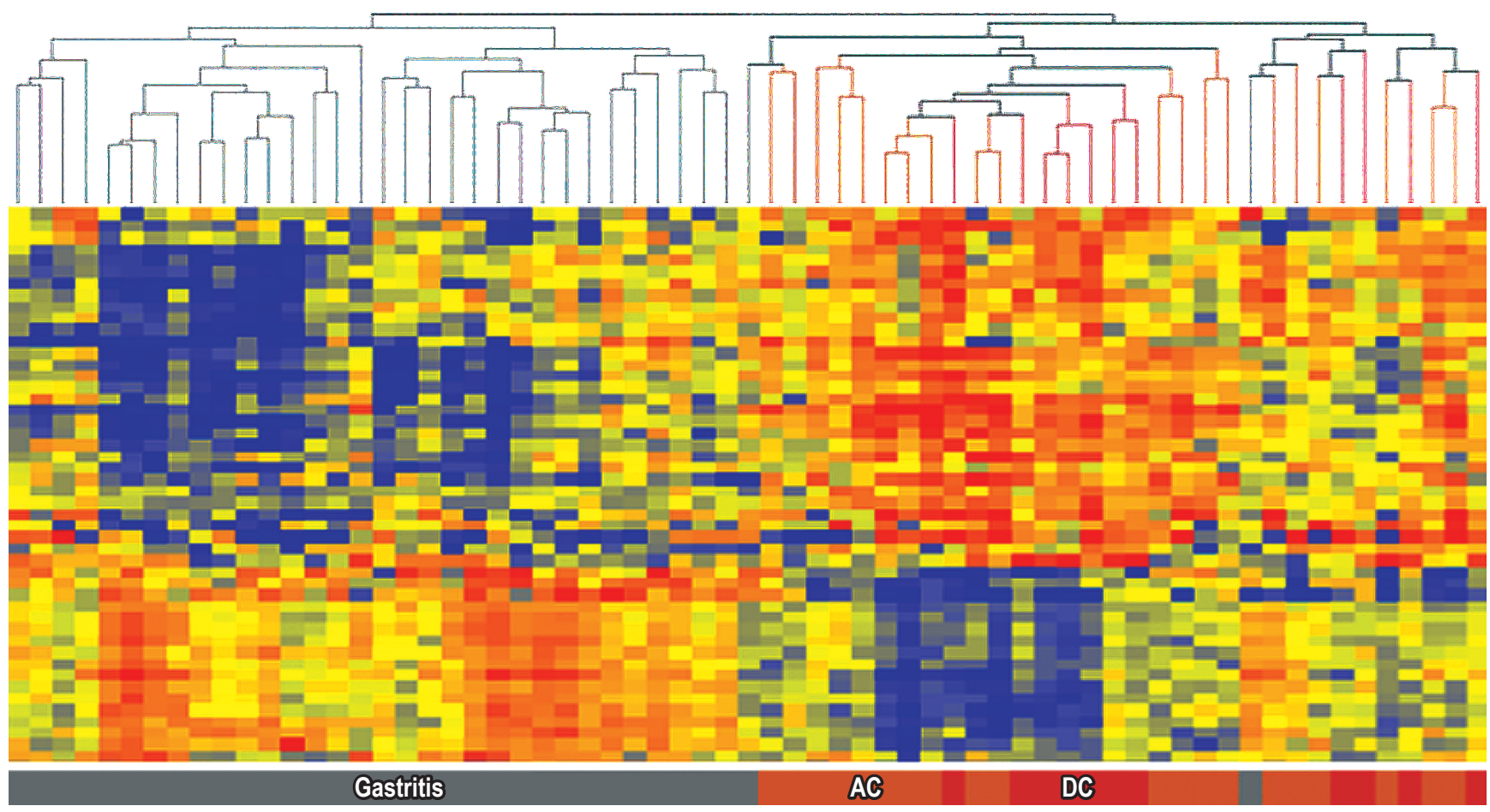

Figura 6. Genes expresados diferencialmente en gastritis comparado con cáncer ( $>1,5$ veces, $p<0,003,49$ sondas). Los valores de intensidad se normalizaron a la mediana de expresión a través de 88 matrices. Rojo/naranja = alta expresión en relación con la mediana; amarillo = expresión medio; azul = baja expresión relativa a la mediana. AC: adenocarcinoma; DC: cáncer difuso. 


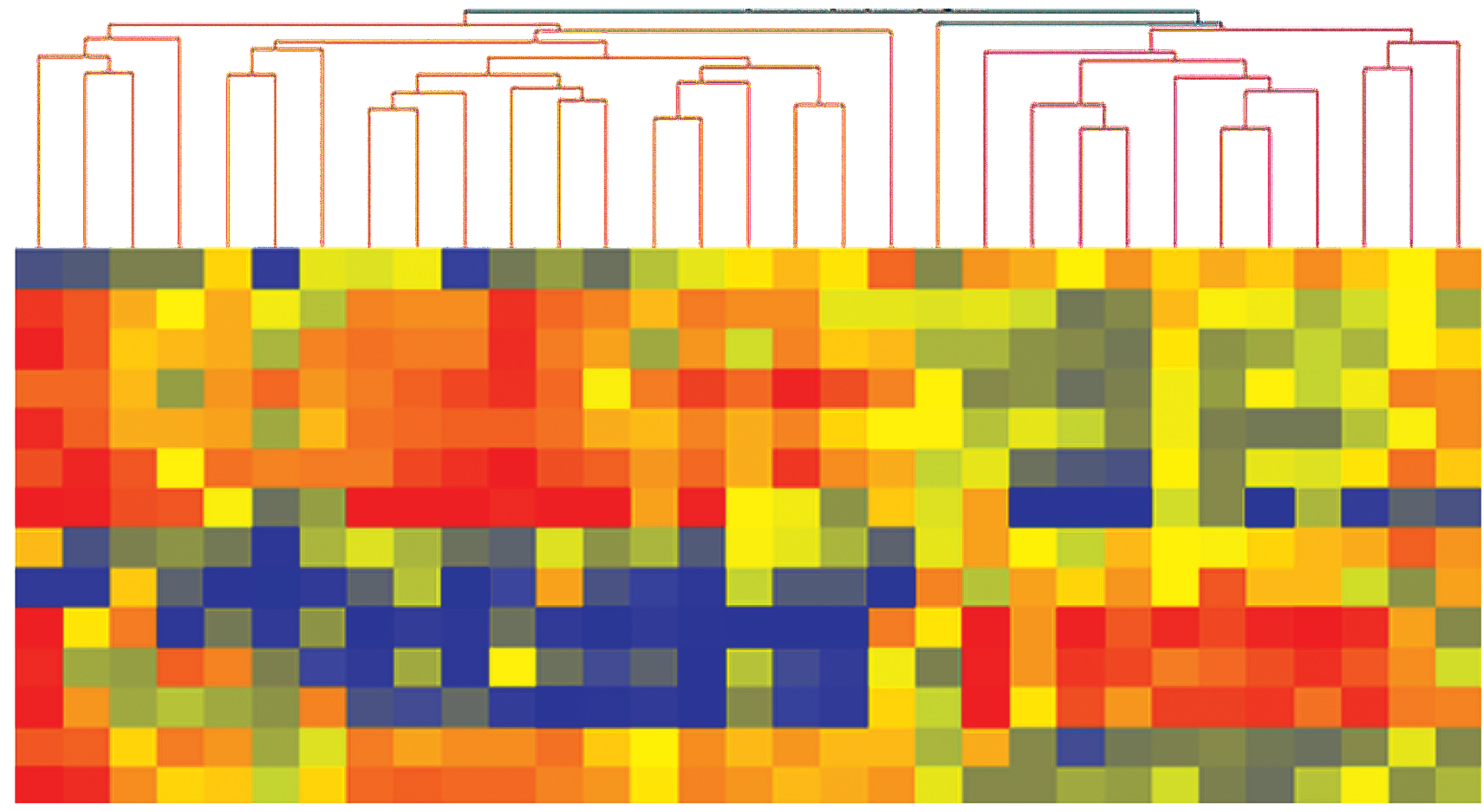

AC

DC

Figura 7. Genes expresados diferencialmente en adenocarcinoma (AC) comparado con cáncer difuso (DC) ( $>1,4$ veces, $p<0,00005$, 14 sondas). Los valores de intensidad se normalizaron a la mediana de expresión a través de 88 matrices. Rojo/naranja = alta expresión en relación con la mediana; amarillo = expresión medio; azul = baja expresión relativa a la mediana.

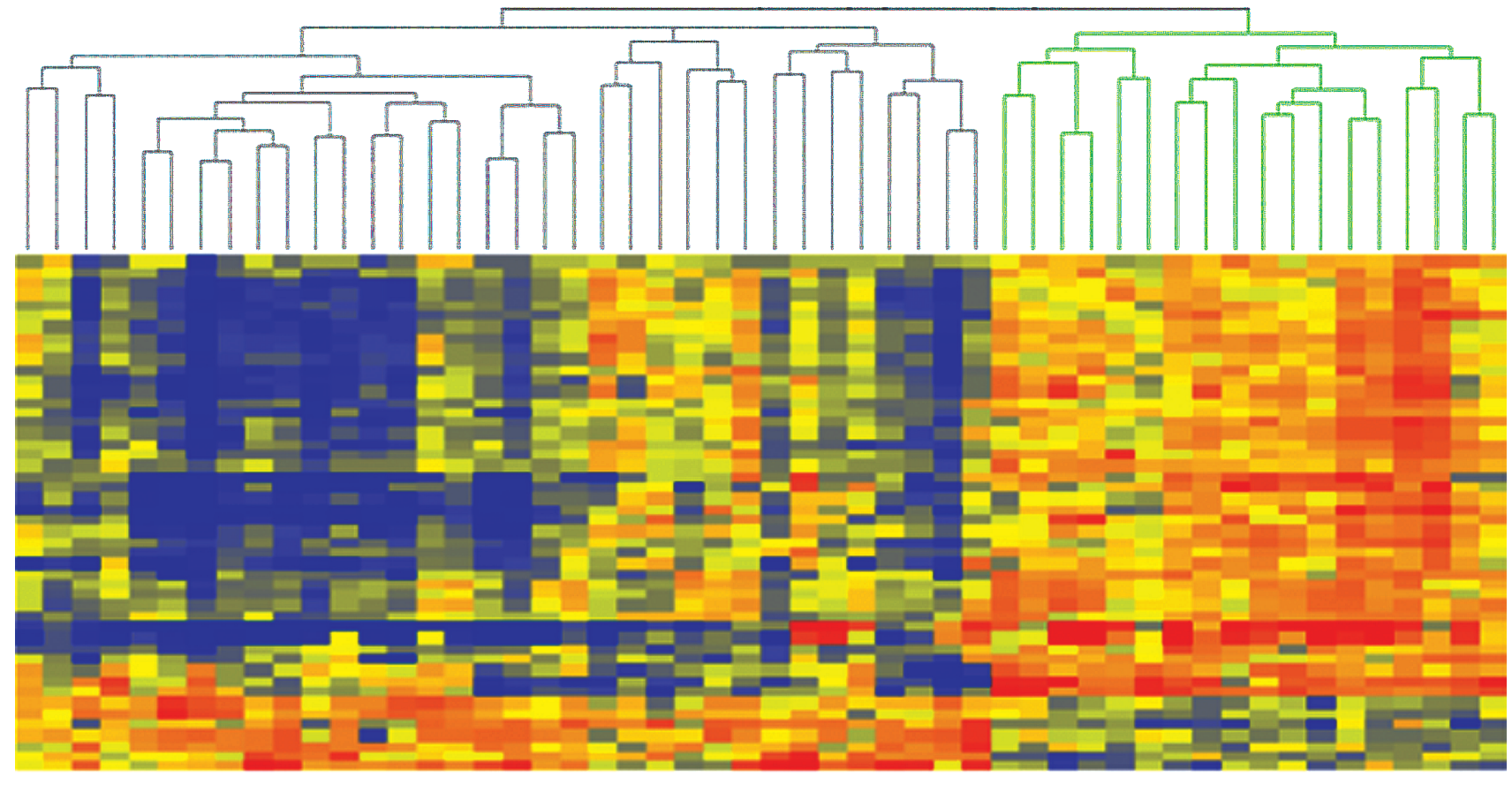

Figura 8. Genes expresados diferencialmente de gastritis frente a metaplasia ( $>1,5$ veces, $p<0,0000001,48$ sondas). Los valores de intensidad se normalizaron a la mediana de expresión a través de 88 matrices. Rojo/naranja=alta expresión en relación con la mediana; amarillo=expresión medio; azul=bajo expresión relativa a la mediana. 
gástrico (3). La detección exacta de las lesiones malignas y premalignas en el estómago, en particular, la atrofia, metaplasia intestinal (MI) y displasia, requiere siempre una endoscopia digestiva alta con toma de muestras de biopsia de acuerdo con un protocolo estandarizado que, con frecuencia, no se sigue en la práctica clínica rutinaria. Además, no se aceptan ampliamente los programas de tamización masiva con endoscopia o fluoroscopia como se hace en Japón, tal vez esta sea una de las explicaciones porque en el mundo occidental la enfermedad se detecta en estados más avanzados con el pésimo pronóstico ya comentado (32).

Por tanto, la información que puedan dar nuevos biomarcadores que permitan estratificar el riesgo de cáncer gástrico es muy importante para aplicaciones a gran escala, sobre todo en poblaciones con alto riesgo de la enfermedad, como Colombia. La intención de este trabajo es la búsqueda de estos biomarcadores y, para conocimiento de los autores, es el primero en Colombia, población de alto riesgo, que permite identifica un perfil de expresión genética en sangre, el cual diferencia claramente pacientes con gastritis de pacientes con cáncer gástrico. La identificación de estos 49 genes permitirá en un futuro diseñar una prueba que diagnostique si un paciente tiene o no cáncer gástrico (figura 1). Además, se logró identificar otro perfil de expresión génica con 14 genes que discrimina si el tumor es difuso o es adenocarcinoma intestinal.

Por otro lado, en el diagnóstico de las lesiones premalignas llama la atención que si bien inicialmente se quiso incluir un grupo de 20 pacientes con atrofia, al comparar las patologías solo había un paciente con atrofia, ya que muchos pacientes que endoscópicamente parecían tener atrofia resultaron con patologías compatibles con gastritis o metaplasia intestinal, lo que confirma que la endoscopia es un método poco sensible para la detección no solo de la atrofia si no de la metaplasia intestinal y, por ello, siempre se debe acompañar con una biopsia.

En cuanto a estas lesiones premalignas, como se discutió, los pepsinógeno se utilizan para el diagnóstico de la atrofia, pero en la literatura no se describen pruebas en sangre para el diagnóstico de la metaplasia. Este trabajo muestra que un perfil de expresión génica conformado por 48 genes (figura 3) permitió diferenciar claramente los pacientes con gastritis de los que tenían metaplasia; lo cual parece fundamental, ya que cada día se sabe que la MI es más importante que la atrofia, y parece ser que es el punto de no retorno en la cascada de Correa teniendo un mayor riesgo de llevar a cáncer que la atrofia, lo que lo hace más importante no solo en su detección si no en su seguimiento $(33,34)$.

Otro aspecto interesante del trabajo es que permite identificar, mediante una prueba sanguínea, a los pacientes que tienen cáncer gástrico, y diferenciarlos entre los dos tipos principales: intestinal y difuso, algo que en la literatura no se había informado y que tradicionalmente solo se puede hacer por una biopsia gástrica, esto parece importante porque en un futuro se podría identificar el cáncer gástrico en un paciente por una prueba de sangre o que estuviera en riesgo del mismo, lo que sería fundamental si se tiene en cuenta que muchos pacientes con cáncer gástrico están asintomáticos cuando se les diagnostica.

Este grupo tiene la intención de utilizar estos perfiles de expresión genética y sus algoritmos clasificadores como herramientas de diagnóstico, ya sea en la forma actual, es decir, usando ARN aislado de sangre entera o, alternativamente, convertirlo en una prueba más rápida y económica mediante el uso de mediciones de los niveles de expresión de un subconjunto de genes o de sus productos proteicos aislados a partir de suero o células sanguíneas. Debido a que el diagnóstico precoz del cáncer o las lesiones premalignas es fundamental en las decisiones clínicas, el uso de estos ensayos podría tener profundas implicaciones para la prevención y el manejo de esta enfermedad, que es muy frecuente en Colombia y que genera una gran mortalidad.

\section{REFERENCIAS}

1. IARC/WHO. Globocan 2012: Estimated cancer incidence, mortality and prevalence worldwide in 2012. Available at: http://globocan.iarc.fr/. Accessed March 31, 2014.

2. Krew KD, Neugut AI. Epidemiology of gastric cancer. World J Gastroenterol. 2006; 12:354-62.

3. Hamashima C, Shibuya D, Yamazaki H, et al. The Japanese guidelines for gastric cancer screening. Jpn J Clin Oncol. 2008;38:259-67.

4. Piñeros M, Hernández G, Bray F. Increasing mortality rates of common malignancies in Colombia. Cancer. 2004; 101:2285-92.

5. Correa P, Piazzuelo MB, Camargo MC. Overview and pathology of gastric cancer. En: Wang T, Fox J, Giraud A (editores). The biology of gastric cancers. Springer Science Business Media. 2009. p. 21-446.

6. Smith MG, Hold GL, Tahara E, et al. Cellular and molecular aspects of gastric cancer. World J Gastroenterol. 2006; 12:2979-90.

7. Moss SF, Malfertheiner P. Helicobacter and gastric malignancies. Helicobacter. 2007;12(1):23-30.

8. Otero W, Gómez M, Castro D. Carcinogénesis gástrica. Rev Colomb Gastroenterol. 2009;24:314-29.

9. Jarvi O, Lauren P. On the role of heterotopias of the intestinal epithelium in the pathogenesis of gastric cancer. Acta Pathol Microbiol Scand. 1951;29:26-44.

10. Lauren P. The two histological main types of gastric carcinoma: diffuse and so called intestinal-type carcinoma. An attempt at a histoclinical classification. Acta Pathol Microbiol Scand. 1951;64:31-49.

11. Correa P, Carneiro F. Classification of gastric carcinomas. Curr Diagn Pathol. 1997;4:51-9. 
12. Ekstrom AM, Serafini M, Nyren O, et al. Dietary antioxidant intake and the risk of non-cardia cancer of the intestinal and diffuse types: a population based case control study in Sweden. Int J Cancer. 2000;87:133-40.

13. El-Omar EM, Lochhead P. Gastric cancer. Br Med Bull. 2008;85:87-100.

14. Henson DE, Dittus C, Younes M, et al. Differential trends in the intestinal and diff use topless of gastric carcinoma in the United States-2000: increase in the signet ring cell type. Arch Pathol Lab Med. 2004;128:765-70.

15. Oliveira C, Seruca R, Carneiro F. Hereditary gastric cancer. Best Pract Res Clin Gastroenterol. 2009;23:147-57.

16. Alberts SR, Cervantes A, van de Velde CJ. Gastric cancer: epidemiology, pathology and treatment. Ann Oncol. 2003; 14(2):ii31-6.

17. Guilford P, Hopkins J, Harraway J, et al. E-cadherin germ line mutations in familial gastric cancer. Nature. 1998;392:402-5.

18. Cisco RM, Ford JM, Norton JA. Hereditary diff use gastric cancer. Cancer. 2008;113(7):1850-6.

19. Masciari S, Larsson N, Senz J, et al. Germline E-cadherin mutations in familial lobular breast cancer. J Med Genet. 2007;44:726-31.

20. Malfertheiner P, Megraud F, O'Morain CA, et al. Management ofHelicobacter pyloriinfection-The Maastricht IV/Florence Consensus Report. Gut. 2012;61:646-64.

21. Correa P. Helicobacter pylori and gastric carcinogenesis. Am J Surg Pathol. 1995;19(1):S37-S43.

22. Bornschein J, Malfetheiner P. Gastric carcinogensis. Langenbecks Arch Surg. 2011;396:729-42.

23. Correa P, Houghton J. Carcinogenesis of Helicobacter pylori. Gastroenterology. 2007;133:659-72.

24. Graham DY, Asaka M. Eradication of gastric cancer and more efficient gastric cancer surveillance in Japan: two peas in a pod. J Gastroenterol. 2010;45:1-8.
25. Piazuelo B, Epplein M, Correa P. Gastric cancer: an infectious disease. Infect Dis Clin N Am. 2010;24:853-69.

26. Guo J, Miao Y, Xiao B, et al. Differential expression of micro RNA species in human gastric cancer versus non-tumorous tissues. J Gastroenterol Hepatol. 2009;24:652-7.

27. Liu Y, Zeng G. Cancer and innate immune system interactions: translational potentials for cancer immunotherapy. J Immunother. 2012;35(4):299-308.

28. Grivennikov I, Florian G, Karin M. Immunity, inflammation, and cancer. Cell. 2010;140(6):883-99.

29. MAQC Consortium. The Microarray Quality Control (MAQC) project shows inter- and intraplatform reproducibility of gene expression measurements. Nat Biotechnol. 2006;24:1151-61.

30. Palayoor T, Aryankalayil M, Makinde A, et al. Differential expression of stress and immune response pathway transcripts and miRNAs in normal human endothelial cells subjected to fractionated or single-dose radiation. Mol Cancer Res. 2014;12(7):1002-15.

31. Martínez T, Bravo M, Núnez D, et al. Niveles séricos de pepsinógeno y su capacidad diagnóstica de atrofia gástrica en diferentes poblaciones colombianas. Rev Colomb Cancerol. 2014;18(4).

32. Danesh J. Helicobacter pylori infection and gastric cancer: systematic review of the epidemiological studies. Aliment Pharmacol Ther. 1999; 13:851-6.

33. Cassaro M, Rugge M, Gutierrez O, et al. Topographic patterns of intestinal metaplasia and gastric cancer. Am J Gastroenterol. 2000;95:1431-8.

34. El-Zimaity HM, Ramchatesingh J, Saeed MA, et al. Gastric intestinal metaplasia: subtypes and natural history. J Clin Pathol. 2001;54:679-83. 